\title{
Chill-inducing music enhances altruism in humans
}

\section{Hajime Fukui* and Kumiko Toyoshima}

Faculty of Education, Nara University of Education, Nara, Japan

\section{Edited by: \\ Andriy Myachykov, Northumbria \\ University, UK}

\section{Reviewed by:}

Lutz Jäncke, University of Zurich Switzerland

Lawrence Mitchell Parsons, University of Sheffield, UK

\section{*Correspondence:}

Hajime Fukui, Faculty of Education, Nara University of Education, Takabatake, Nara 630-8528, Japan e-mail: fukuih@nara-edu.ac.jp

\begin{abstract}
Music is a universal feature of human cultures, and it has both fascinated and troubled many researchers. In this paper we show through the dictator game (DG) that an individual's listening to preferred "chill-inducing" music may promote altruistic behavior that extends beyond the bounds of kin selection or reciprocal altruism. Participants were 22 undergraduate and postgraduate students who were divided into two groups, the ingroup and the out-group, and they acted as dictators. The dictators listened to their own preferred "chill-inducing" music, to music they disliked, or to silence, and then played the DG. In this hypothetical experiment, the dictators were given real money (which they did not keep) and were asked to distribute it to the recipients, who were presented as stylized images of men and women displayed on a computer screen. The dictators played the DG both before and after listening to the music. Both male and female dictators gave more money after listening to their preferred music and less after listening to the music they disliked, whereas silence had no effect on the allocated amounts. The group to which the recipient belonged did not influence these trends. The results suggest that listening to preferred "chill-inducing" music promotes altruistic behavior.
\end{abstract}

Keywords: music, emotion, altruism, empathy, prosocial behavior, dictator game

\section{INTRODUCTION}

On March 11, 2011, Japan experienced an unprecedented disaster in which many people lost their families and homes in an instant. However, in the midst of this terrible situation, we witnessed behavior again and again that seemed unusual. For survivors, who were in the depths of despair, it appeared that music had the power to inspire courage and cooperation in them. This has also been the case throughout the period since the disaster. Countless concerts have been held not only in the affected areas but throughout Japan and worldwide to mourn for those who lost their lives and express hope for recovery (e.g., The Japan Foundation, 2012). There are times when people sacrifice their own interests to help others, but such prosocial behavior is typically expressed through financial donations or voluntary work (Miller et al., 1991). Music does not usually appear to be associated with "prosocial behavior."

As is widely known, music has the ability to strongly affect a person's emotions and sometimes even control them (Juslin and Sloboda, 2010), though science has not yet provided an explanation for this phenomenon. Darwin (1871) noted the mysterious quality that lies in man's capacity to create music (Fitch, 2006). Indeed, what is the true value of music, which fascinates many scientists, if it does not have an adaptive function or survival value? The ability of music to absorb and captivate people remains an enigma.

The emotions induced by music have attracted the attention of numerous researchers (Budd, 1985; Juslin and Sloboda, 2010). In addition, it has been shown that music can arouse various complex emotions that are both positive and negative (Trost et al., 2012) as well as either pleasant or unpleasant (Koelsch et al., 2006). However, studies regarding emotion and music have primarily focused on listening and there are limited studies that have compared emotions evoked by performing and listening to music.
According to the study by Nakahara et al. (2011), by modulating emotion-related autonomic nerve activity, musical performance can be more effective than musical perception (listening) in musicians. However, it remains unclear whether there is difference between emotion evoked by performing or listening. Recent studies have revealed that the emotions evoked by listening to music can modulate activity in all the limbic and paralimbic brain structures, and that those emotions tend to be stronger than everyday feelings or moods; therefore, they are registered as a strong experience (Koelsch et al., 2010) and are associated with particular brain activity (Koelsch et al., 2006).

It has been proposed that human altruism is engendered by empathy (Silka and Housea, 2011). If, as the above research suggests, emotional changes elicited by music activate empathy circuits in humans, music would also be expected to enhance altruistic behavior.

Several studies have examined music and altruism, or prosocial behavior (Kirschner and Tomasello, 2010; Kokal et al., 2011). Joint drumming in a social condition (drumming together with a partner) facilitates synchronization in preschool children and elicits a specific human motivation to synchronize movements during joint rhythmic activity (Kirschner and Tomasello, 2009). In addition, music making, including joint singing, encourages participants to maintain a collective intention and shared goal of vocalizing and moving together in time, thereby effectively satisfying the intrinsic human desire to share emotions, experiences, and activities with others (Kirschner and Tomasello, 2010). Several studies have indicated that music listening can mediate several behaviors related tangentially to altruism, such as maintaining low levels of classroom noise (Wilson and Hopkins, 1973), aggression (Konečni et al., 1976), and spending money in the school cafeteria (North and Hargreaves, 1998). 
Listening to music can be a highly rewarding experience for humans. Although there has been little research in the field of music psychology, psychology, and neuroscience, studies have shown that a positive mood increases prosocial behaviors. Empirical evidence has revealed the effects of moods on behavior and many studies have shown that moods can affect a person's behavior (Wright and Bower, 1992; Gendolla, 2000) or decision (Schwarz, 2000; Lerner et al., 2004; McEwen, 2012). There have also been reports that both positive and negative moods promote altruism and prosocial behaviors (Batson, 1991; Dovidio et al., 2006). It has been found, for example, that audiotapes can induce positive moods, thereby increasing altruism and thus giving rise to prosocial behavior (economic games; Capra, 2004). Prosocial songs were associated with a significant increase in tipping behavior (Gueguen, 2001). Fried and Berkowitz (1979) found that soothing (classical) music promoted greater levels of altruism (offering help to others) than did either aversive music (such as modern jazz) or no music. Anshel and Kipper (1988) reported that group singing (popular songs) promoted trust and cooperation among participants in an experiment. North et al. (2004) found that uplifting music (background music) led to participants' offering more help on an expensive, leaflet-distributing task, than did annoying music.

There are few studies, however, that have directly investigated the relationship between the emotions evoked by music (strongly positive or negative emotions) and prosocial behavior or altruism. Similarly, no study related to music has focused specifically on the dictator game (DG). The DG shows the altruistic tendency most clearly, and it is the most well-known paradigm, one used frequently by economists, to test the existence of altruism (e.g., Bolton et al., 1998; Camerer and Fehr, 2006; Knafo et al., 2008; Henrich et al., 2010). We used the DG (with music as the background stimulus condition) in order to explore the relationship between the emotions evoked by listening to music and altruistic tendencies.

\section{MATERIALS AND METHODS PARTICIPANTS}

Participants in this double-blind experiment were 11 healthy men (aged 19-23 years, mean age 21 years) and 11 healthy women (aged 19-23 years, mean age 21 years), mainly recruited from among undergraduate and postgraduate students. Because it has been demonstrated that the menstrual cycle of women influences their behavior in economic games (Pin and Fletcher, 2011), the experiment was conducted in the follicular phase (within 6 days after the end of menstruation) for the female participants to standardize this variable. All gave written informed consent to participate in this study based on the Declaration of Helsinki (2000) and the University Research Ethics Standards.

Since this study examines the overall impact of listening to music on altruism, we eliminated the professional musicians. The remaining subjects were considered to be those from the general population who had an average of 9.9 years of experience in music (instrumental or vocal) either through music education classes or individual study. We conducted a preliminary survey to investigate whether potential participants had ever experienced "chills," a powerful music-induced emotional experience, which is used by many researchers as a subjective indicator of the experience of feeling music (e.g., Gabrielsson, 2001; Hodges, 2010; Nusbaum and Silvia, 2010). Only those who responded affirmatively were selected as participants.

\section{BRIEFING SESSION}

In the briefing session, participants completed a number of tests and a questionnaire that addressed their musical tastes and emotional experiences through music. Questionnaires included the NEO Five-Factor Inventory (NEO-FFI), the Cambridge Behavior Scale (Empathy Quotient; EQ), and the State-Trait Anxiety Inventory (STAI-state and STAI-trait).

The NEO-FFI is a shortened version of the NEO Personality Inventory-Revised (NEO-PI-R), which measures five domains of personality: openness to experience, conscientiousness, extroversion, agreeableness, and neuroticism. The NEO-FFI measures these domains using a 60-item questionnaire and a 5-point response scale from "strongly agree" to "strongly disagree" (Costa and McCrae, 1992). The Cambridge Behavior Scale measures scores on empathy (EQ). This test is comprised of three subscales: cognitive empathy, emotional reactivity, and social skills. It uses a 60 -item self-reporting, 4-point scale ranging from "strongly agree" to "strongly disagree" (Baron-Cohen and Wheelwright, 2004). The STAI consists of Form I, which measures state anxiety, and Form II, which measures trait anxiety. Each form contains 20 items, for a total of 40 items (Spielberger et al., 1970). Participants responded on a 4-point scale from "very much" to "not at all." The STAI-I was administered before and after the stimulus presentation in this experiment.

We analyzed the correlation between the preliminary survey scores for the NEO-FFI, the EQ, and the STAI questionnaires and the changes in allocated amounts in the DG before and after stimuli, but found no significant influences.

\section{DICTATOR GAME}

Participants were informed of the basic rules and the concept of the game prior to the experiment. They were divided into two groups of 11 members each, according to the lots they drew, and the groups were named the in-group (IG) and the out-group (OG), the dictators and the recipients, respectively. They were also told that every participant in each group would take part in the DG as dictator.

The participants then assembled with the members of their group, facing a computer screen that displayed a mark identifying their group (a vertical or horizontal line). This was done to make the participants aware that there were two different groups and to heighten their sense of belonging to their own group. Also, in order to encourage the participants to self-identify and feel a strong social identity with their groups, they wore T-shirts with logos of their group on the front, which clearly indicated who belonged to the IG and who belonged to the OG (Gino etal., 2009).

Each participant played the dictator's role in the DG. There were four recipients in total: one male and one female who belonged to the IG, and one male and one female who belonged to the group OG. 
In the DG, information about the recipients (e.g., attractiveness) can affect the decision of the dictator (Aguiar et al., 2008; Rosenblat, 2008); therefore, we eliminated these factors as much possible by ensuring that the dictators did not see the recipients. The recipients in the experiment were stylized images of male and female humans shown as black-and-white figures, whose only identifying features were sex and group, thus eliminating the factor of attractiveness. These images were displayed on a 19-inch computer screen placed in front of the dictators (Figure 1).

This experiment was hypothetical, as the dictators were given real money, but were not permitted to keep the money. Previous studies have shown that reward type (real or hypothetical) made no significant difference in cooperation. The dictator will allocate money even if the experimenters do not use pecuniary incentives, and that the effect of the manipulation is insignificant (e.g., Aguiar et al., 2008; Ben-Ner et al., 2008; Engel, 2011; Locey et al., 2011; Radke and de Bruijn, 2012).

\section{MUSIC}

Musical emotions are induced through a complex interaction between the music, the listener, and the environment, and are influenced by factors such as personality and culture (Sloboda and Juslin, 2010). A variety of methods have been used to investigate musical emotions, but one highly reliable approach centers around the concept of "chills," which many researchers use as a subjective indicator of musical feeling (e.g., Hodges, 2010; Nusbaum and Silvia, 2010; Balteş et al., 2011). "Musical chills" are a phenomenon involving strong affective changes such as
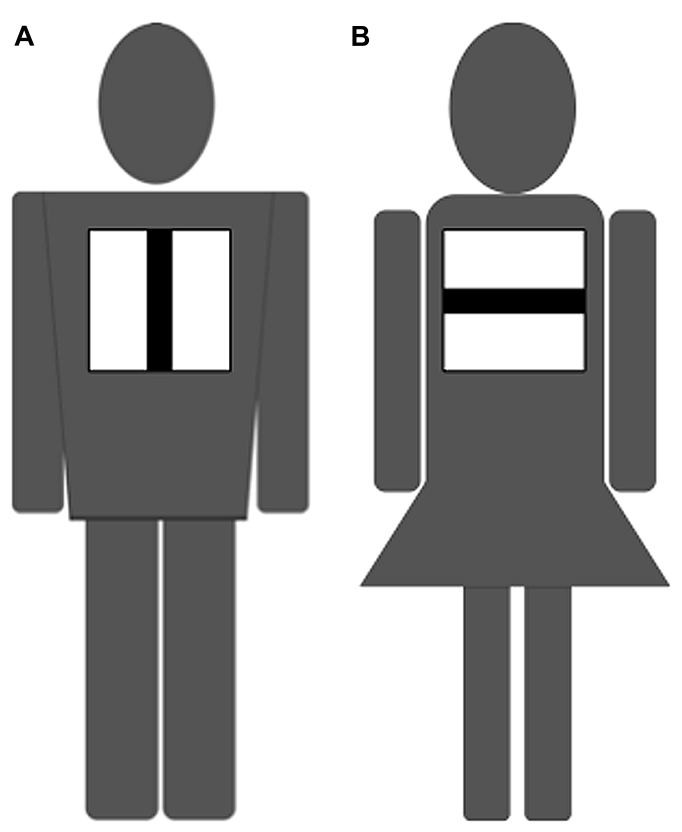

FIGURE 1 | Stylized recipient in Dictator Game (DG). These images are recipients in the DG experiment, displayed on a 19-inch screen in front of the dictator. Four types of recipients were created through a combination of the recipient's sex (man or woman) and group membership (vertical group or horizontal group). (A) One of the four patterns: a man belonging to the vertical group. (B) A woman from the horizontal group. tears, shivers down the spine, and goose bumps (Gabrielsson and Lindström, 2003). However, not everyone experiences musical chills (Salimpoor et al., 2009). For this reason, we recruited individuals who had experienced "chills" as an intensely pleasurable response to music (Salimpoor et al., 2009), as noted earlier.

For this experiment, we asked the participants to choose two types of music in advance: (1) music they preferred (chillinducing) and (2) music they did not like. We used silence as the third condition. The participants took part in all sessions ( 3 stimuli $\times 4$ games). In this experiment, the same musical pieces (preferred and disliked) were repeated four times (same sex: IG and OG, opposite sex: IG and OG), and the orders were randomized. Until the start of the experiment, the participants were not informed which stimulus would be presented or with whom they would play the DG.

The three categories of stimulus were each presented for $5 \mathrm{~min}$, and the participants who had selected music lasting more than 5 min were asked to choose a 5-min passage that contained the most chill-inducing or most disliked part within the piece. About half of the music that the participants chose as preferred music (chill-inducing) was Japanese pop, and the remainder included classical piano and orchestral music. Disliked music included contemporary music, traditional Japanese music, Enka (sentimental ballads), and computer game music. There were a roughly equal number of vocal and instrumental pieces.

The participants listened to the music on headphones. Stimuli were presented as MP3 files (sample-rate $44.100 \mathrm{kHz}$ ) that were played on a computer. For the silent control condition, participants wore headphones in the same way as when listening to music.

\section{EXPERIMENTAL PROCEDURE (FIGURE 2)}

On the day of the experiment, participants took part in the DG sessions. Participants were first instructed to put on the T-shirts printed with a logo that identified their group to heighten their sense of group belonging. They then completed the STAI-state and played the DG before and after the stimulus presentation (preferred music, disliked music, or silence). At the end of each session, participants were asked to rate their feeling of "chill" toward the stimulus on a 7-point scale from "completely unmoved" to "highly moved." Simultaneously, participants expressed what and how they felt during the experiment through freewriting. Each session lasted about $20 \mathrm{~min}$. In order to avoid the influence of an experimenter's sex, the experimenter who gave the instructions was the same sex as the participant.

At the start of each game, the dictator was given cash $(10,000$ Japanese yen) and instructed to allocate this fund between him/herself and the recipient in units of 1,000 yen. Before making the allocation, the dictator was discreetly told that as the dictator, it was up to him/her what to do with the money. The allocation was entirely at the dictator's discretion. The recipient had no right to receive or to refuse the allocation, and therefore the dictator was entirely free to give money to the recipient or not. While the recipient was displayed on the computer screen, the dictator checked and verbally reported to the experimenter whether the recipient was a man or a woman, and whether the recipient belonged to the same group as the dictator or not. 


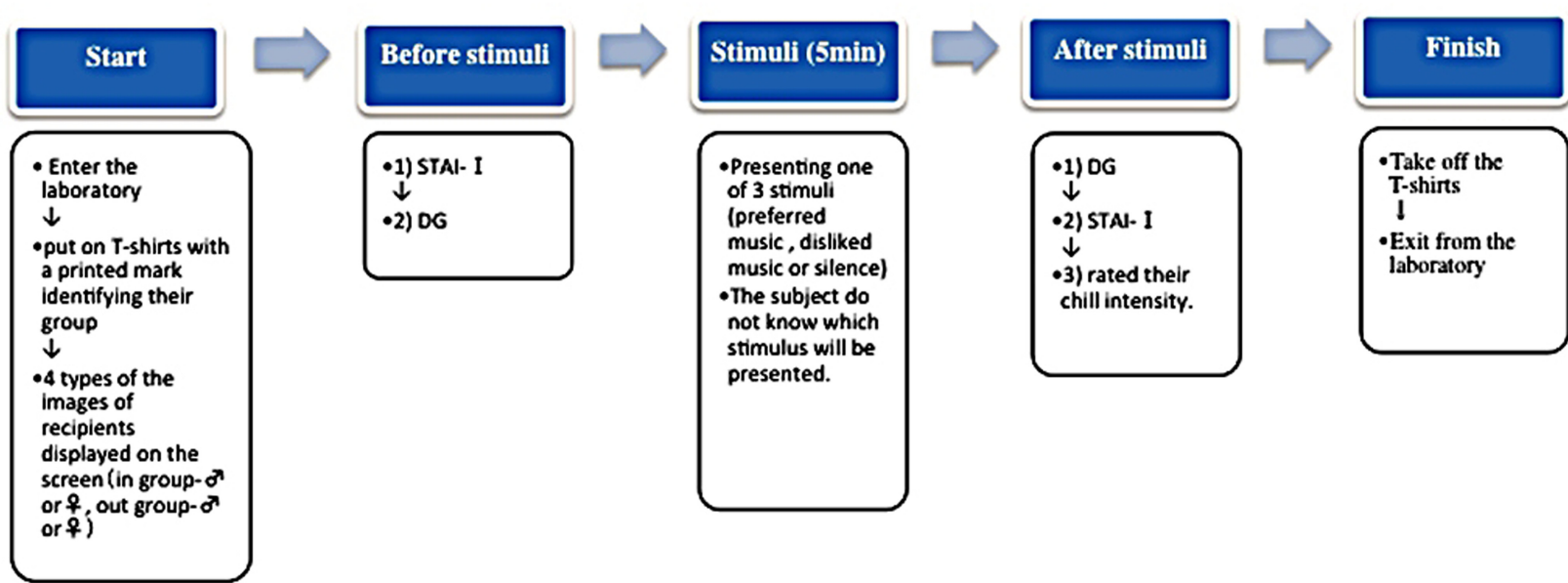

Total time of each session : $15-20 \mathrm{~min}$

FIGURE 2 | Sequence of events in the experiment. The above diagram shows the flow of a single session. The time required for one session was about $20 \mathrm{~min}$. All participants participated in 12 sessions (3 stimuli: preferred music, disliked music, and silence $\times 4$ DG games). Sessions were separated by rest periods of at least $30 \mathrm{~min}$ in order to counteract the effects of the previous session. The participants participated in 3-4 sessions per day, and the experiment was carried out over 3-4 separate days.
Dictators were then instructed to allocate the money. Before the participant's first actual game, we administered two training games and checked whether the participant understood the rules.

To avoid interference, the experimenter withdrew to another room before the allocation so that the dictator could decide how much to give at his/her own discretion. In addition, the dictator directly put the divided cash into a cash box and locked it with a dial lock so that the experimenter could not know the allocated amount.

Each participant played the game in his/her assigned role as the dictator with each of the four recipients (one man and one woman of the IG; one man and one woman of the OG) under each of the three stimulus conditions (two types of music, or silence), for a total of 12 sessions. In the control condition, the procedure was exactly the same as the music condition except that the dictators did not listen to any music (i.e., silence was used).

Sessions were separated by rest periods of at least $30 \mathrm{~min}$ to avoid carryover effects (fatigue). Also, to help the participants avoid fatigue, the experiment was carried out in 3-4 sessions per day over 3-4 separate days. In order to avoid the order effect, the presentation of stimuli ( 3 stimuli $\times 4$ games) was randomized.

As noted previously, in the DG, information about the recipients (e.g., attractiveness) can affect the decision-making of a dictator (Aguiar et al., 2008; Rosenblat, 2008). Therefore, to eliminate these effects as much as much possible with regard to who played the music, after the experiment, the dictators were asked a multiple-choice question: "who was playing the music?" The possible responses were: (1) the dictator, (2) the recipient, or (3) the music was played in the setting where the DG was carried out. None of the dictators thought that they themselves or the recipients had performed the music, and believed that it was played in the environment where the DG was carried out. Therefore, the researchers were assured that any bias was eliminated.

\section{RESULTS}

The DG (allocation) was analyzed through a four-way repeatedmeasures analysis of variance (ANOVA) with the following factors: "music" (chill-inducing, dislike, silence as control), "recipient's group" (IG, OG), "recipient's sex" (male, female), and "subject's sex" (male, female). As a measure of effect size ETA ${ }^{2}$ is reported. Regarding a significant multivariate effect, post hoc paired $t$ tests were computed using the Bonferroni correction. The results showed that allocation behavior before each of the three stimuli was the same as the behavior that is consistently seen in past studies of the DG (Engel, 2011). However, the present experiment showed that the allocation was significantly different after stimuli presentation, depending on whether the stimulus was silence, preferred (chill-inducing) music, or disliked music. The average DG-allocations are presented in Table 1. The ANOVA (DGs $\times 3$ stimuli) revealed a significant interaction $[F(2,240)=69.019$, $\left.p=0.001, \mathrm{ETA}^{2}=0.6\right]$ that both male and female dictators gave more money after listening to their preferred music and less after listening to their disliked music (Bonferroni $p=0.009$ ), whereas silence had no effect on the allocated amounts (Figure 3 ). The group to which the recipient belonged did not influence these tendencies. However, the ANOVA (DGs $\times$ group) revealed that the 
Table 1 | Mean allocation of each stimuli.

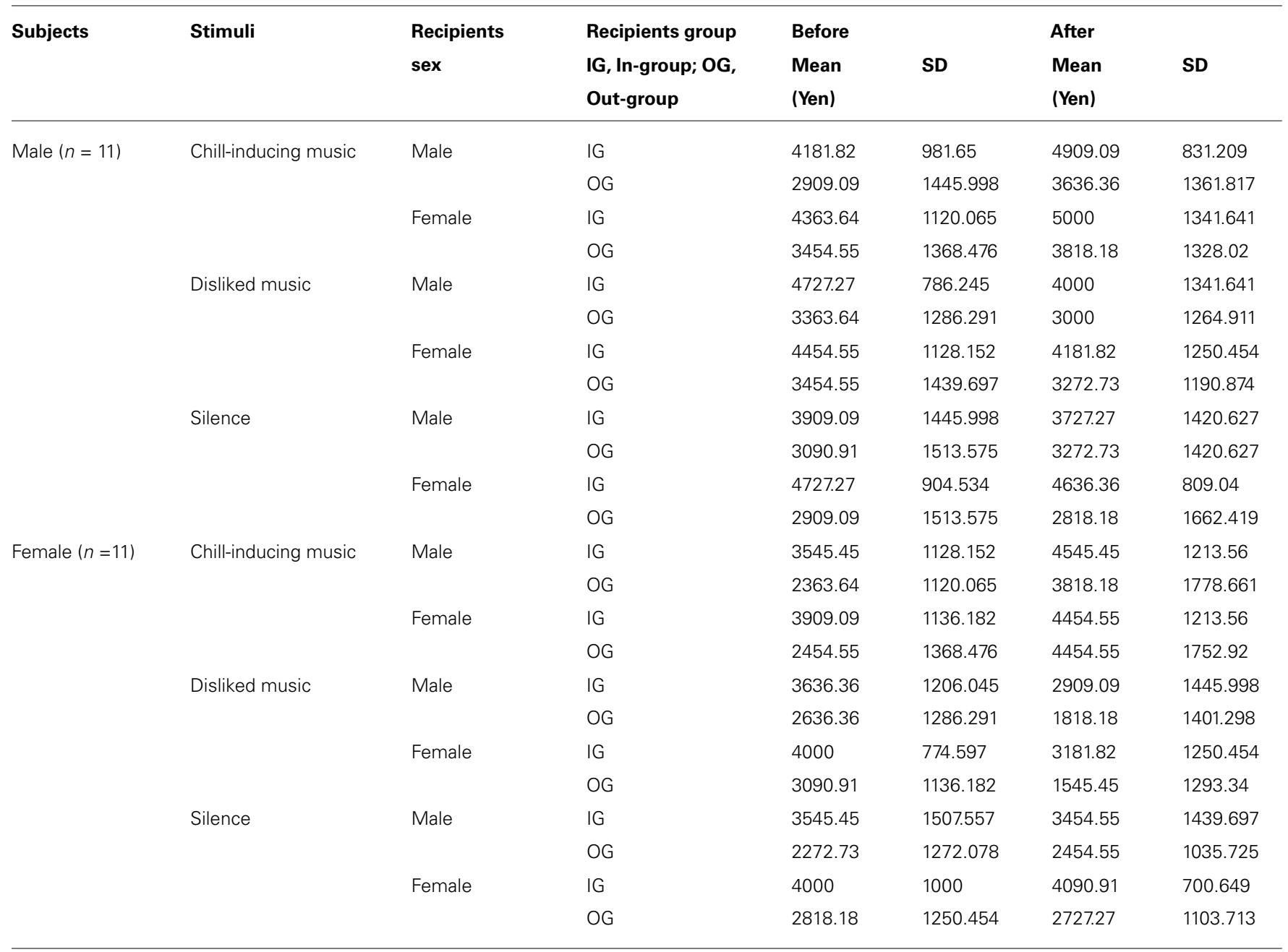

actual amount that was allocated differed depending on whether the recipient belonged to the IG or the OG $[F(1,240)=57.679$, $p=0.001$. ETA $^{2}=0.3$; Bonferroni $\left.p=0.001\right]$. Male dictators also gave higher amounts than female dictators (DGs $\times$ sex) $\left[F(1,240)=16.141, p=0.001\right.$, ETA $^{2}=0.1$; Bonferroni $\left.p=0.001\right]$. The STAI-state (STAI points $\times 3$ stimuli) revealed a significant interaction $\left[F(2,240)=28.196, p=0.001\right.$, ETA $\left.^{2}=0.3\right]$ that preferred music decreased anxiety, while disliked music increased anxiety (Bonferroni $p=0.001$ ). We analyzed the changes in allocated amounts in the DG to see if they were affected by the presence or absence of words in the music, but ANOVA revealed no significant differences. Participants chose both vocal and instrumental music, but the ANOVA revealed no correlation between the results for either the type of music or the level of musical experience.

In a post-game session, a survey was taken, and all participants responded that they had experienced chills (highly moved: rating of 6 or 7 on a 7-point rating scale) when listening to their preferred music and were unaffected (completely unmoved: rating of 1 or 2 on a 7-point rating scale) when listening to their disliked music. No correlations were found with the NEO-EFI, EQ. There were no such comments found in what the participants wrote about their feelings during the experiment, which could have influenced the results.

\section{DISCUSSION}

Decision-making in humans is strongly influenced not only by logic but also emotion (Coricelli et al., 2007). In the experiment, after listening to their preferred (chill-inducing) music, the dictators increased the amount of money allocated to the recipient regardless of whether the recipient was in the IG or OG, whereas they decreased the amount after listening to disliked music, no matter which group the recipient belonged to. The actual amount allocated differed between IG and OG recipients; dictators distributed more to the IG than to the OG. As noted, this experiment was hypothetical, though the results are consistent with a previous study (Forgas and Fiedler, 1996). However, after listening to music, the dictators showed no difference or preference, as seen in the allocation that they made. This shows that music can activate both altruistic behavior and selfish behavior. It is vital to note that music affects an individual's behavior greatly; preferred music promotes altruistic behavior, whereas disliked 


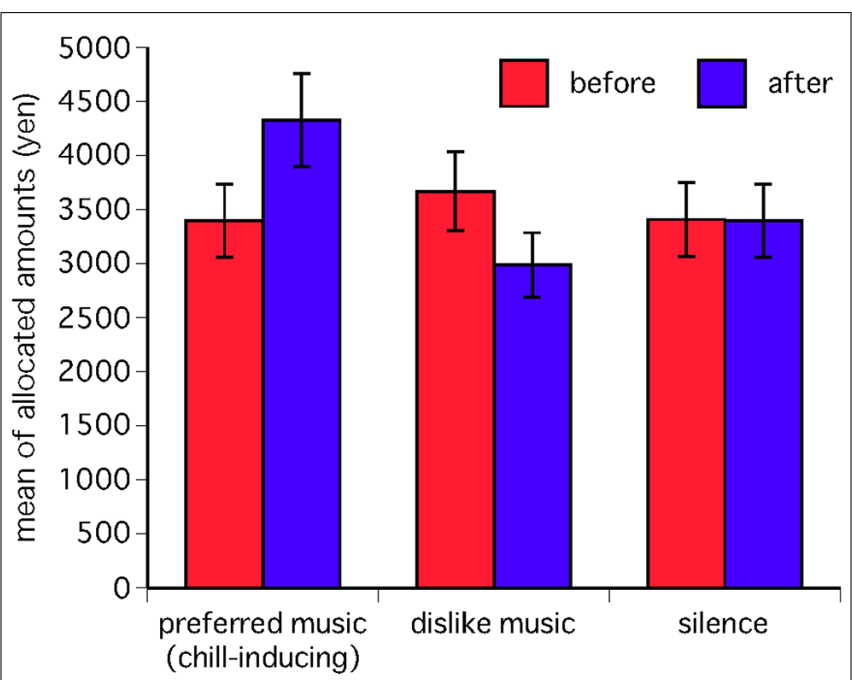

FIGURE 3 | Changes in allocation of DG money before and after stimulus. This graph shows changes in the amounts allocated to recipients before and after presentation of three types of stimuli (preferred music, disliked music, and silence) in a DG experiment played by 11 male and 11 female participants (Error bars show SD). The amount allocated to recipients significantly increased after participants listened to their preferred music, but decreased after they listened to their disliked music $[F(2,240)=69.019, p=0.000]$.

music is associated with selfish behavior, and what differentiates these behaviors is the emotional response dictated by the listener's musical preferences.

Emotions induced by music are thought to be associated with the action of mirror neurons and the limbic system (Zatorre and McGill, 2005). Thus, the internal experience of music may be mediated by the human mirror neuron system (Overy and Molnar-Szakacs, 2009). Studies involving musicians and dancers have also reported that the internal experience of music modulates the activity of the human mirror neuron system (D'Ausilio et al., 2006). Mirror neurons have been linked to the higher brain function of empathy, and it has been suggested that the emotional response to music is also an empathic process resulting from listening to a performance by other humans (Chapin et al., 2010). Many reports have indicated that the mirror neuron system is related to empathy (Overy and Molnar-Szakacs, 2009; Decety, 2011), which is also a central mechanism of music-induced emotions (Juslin et al., 2010). However, even though the presence of the inferior frontal cortex and superior parietal lobe is assumed, the existence of mirror neurons in the human brain has not yet been confirmed.

There are many neurophysiological studies that have shown how visual stimuli evoke emotions. Moreover, there are reports that strong emotion enhancement affects the simultaneous presentation of congruent emotional pictures and music (Baumgartner et al., 2006, 2007). In addition, visual bias (attractiveness) induces IG favoritism in behaviors (Ratner et al., 2014). As stated earlier, in the DG, information about the recipients (e.g., attractiveness) can affect the decision of the dictator (Aguiar et al., 2008; Rosenblat, 2008). In this regard, we applied stylized (black-and-white) images of males and females whose only identifying features were sex and group, to eliminate the factor of attractiveness. Thus, it is believed that the results were caused by music with strong emotions (chill-inducing music) that was presented concurrently with such visual information.

Research on the affective influences of altruism and helping behavior has remained largely inconclusive. Studies suggest that both positive and negative effects can promote altruism and prosocial behaviors, and that the results depend upon the circumstances (Dovidio et al., 2006). In the present experiment, music elicited emotional reactions (decreasing or increasing anxiety: STAI-state), which can be interpreted as positive and negative moods (Rossi and Pourtois, 2012). A positive mood induced by preferred music promoted altruistic behavior, whereas a negative mood induced by disliked music increased selfish behavior. This result does not match the previous finding that a negative mood can also increase altruistic behaviors (Capra, 2004; Tan and Forgas, 2010). Musical emotions are difficult to define scientifically, but at the very least, we can say that preferred music elicits chills, while disliked music does not. That is to say, the emotion evoked by musical stimuli (chill) is distinct from everyday emotion (mild mood; Patel, 2008), and it causes strong emotional responses. It may be that the dictators behaved altruistically toward others because they experienced positive musical emotions, which activated the brain's reward system, which is centered in the limbic system, and simultaneously activated the empathy circuits. Key brain regions for processing musical emotions are the striatum, the amygdala, the orbitofrontal cortex, and the anterior cingulate cortex (Zatorre and McGill, 2005).

In contrast, self-interested behavior may have occurred as a result of the dictators' listening to disliked music. The aversive stimulus may have induced negative musical emotions that activated other reward circuits (the ventromedial orbitofrontal cortex and the amygdala, the ventral striatum, and the ventromedial prefrontal cortex; Tricomi et al., 2010). The amygdala appears to be necessary for the emotional processing of music (Gosselin et al., 2007; Rand et al., 2012).

Strong emotions such as chill responses to music are linked to an activation of the sympathetic nervous system and the brain reward circuits. The chill response occurs in the auditory domain in the context of highly pleasurable events (music) that lead to the activation of the dopaminergic reward system in the brain (D'Ausilio et al., 2006). Salimpoor et al. (2009) found that there is an endogenous dopamine release in the striatum at peak emotional arousal during music listening ("chills"). Conversely, sad music, in contrast to neutral music, activated the hippocampus and the amygdala, consistent with the role of these structures in negative emotion perception (Gosselin et al., 2007; Lerner et al., 2009), and the cerebellum (Brattico et al., 2011). Increasing chill intensity decreases regional cerebral blood flow in the amygdala (Blood and Zatorre, 2001; Matthews et al., 2009).

Again, the amygdala is necessary for developing and expressing normal interpersonal trust (Koscik and Tranel, 2011). A study has shown that when the amygdala is damaged in an individual, that person invests more money with other people who are unfamiliar than do healthy controls (van Honk et al., 2013). Therefore, in this experiment, suppression of amygdala activity by chill-induced 
music might lead to a dictator's increasing the distribution of money.

In the experiment, male dictators gave higher amounts than did female dictators regardless of the type of music, relationship to the recipients, or sex of the recipients. Research on sex (gender) differences in generosity or prosocial behavior has been contradictory. It is widely believed that females are more sensitive than males to "costs" (Riyanto and Zhang, 2010). Although both sexes prefer direct cooperative behavior toward more attractive members of the opposite sex (Farrelly et al., 2007), this result was easily predictable. The recipients of the experiment were therefore stylized images of male and female humans, whose only identifying features were sex and group, thus eliminating the factors of attractiveness. Our results, therefore, can be considered as consistent, and they were not affected by the appearance of the recipients. Males' showing more generosity corresponds to the results of previous studies.

Musical ability is known to have a genetic component (Wallin et al., 2000), but the environment in the form of cultural variation also has a great influence. In essence, musical preferences are probably influenced by genetics and experience, but the degree of cultural difference, and diversity in music is probably much greater today than for early humans, who lived in small groups based on kinship. For them, the music of one's group would probably have been the music an individual preferred and found emotionally moving. If a total stranger performed this preferred music, it would suggest a kinship or some other connection to one's own group. It would therefore be rational to treat the stranger altruistically. Similarly, disliked music would suggest a weak connection and would justify selfish behavior. In our experiment, the recipients were identified by a logo indicating which group they belonged to. After listening to their preferred music, dictators treated the recipients wearing IG logos altruistically, but after the dictators heard disliked music, their behavior was selfish. Despite the dictators' being in the same group as the recipients, the emotions caused by music led to changes in their allocation. The dictators also behaved altruistically toward the recipients in the OG after listening to preferred music. This behavior was somewhat illogical. Considering that in the pre-stimulus DG, dictators allocated money in the usually observed way (Forsythe et al., 1994; Bolton et al., 1998), this altruistic action toward the other group is remarkable.

All dictators thought that the music was being played in the setting in which they were facing their recipient. In this situation, the dictators would not have made their decisions on the basis of reciprocal altruism, because of the low probability of getting a reward from an OG recipient. Thus, the decisions that the dictators made after listening to their preferred music (which can be construed as listening to music played by members of the IG) might explain a unilateral altruistic behavior toward the OG. Tomasello et al. (2005) suggested that humans have a speciesunique motivation to share emotions, experiences, and activities with other persons. Merker (2000) suggested that synchronous chorusing by hominid males served as an indicator of coalition strength, helping to defend territory and at the same time attract migrating females. Hagen and Bryant (2003) proposed that group music making (and dancing) evolved as between-group displays signaling internal stability and the group's ability to act collectively, thereby establishing meaningful relationships - whether cooperative or hostile-between groups. Kirschner and Tomasello (2010) asserted that music (making) has a positive effect on prosociality and that its effects can be interpreted as evidence against the hypothesis that today's music (and dance) are completely nonadaptive byproducts of the human mind. Our results showed that preferred music can promote cooperative behavior between groups.

Altruism is a recognized feature of human society, and it goes far beyond that which has been observed in the animal world (Fehr and Fischbacher, 2003), and extends beyond reciprocal altruism and reputation-based cooperation, taking the form of strong reciprocity (Gintis, 2000; Fehr et al., 2002). Musical emotion seems to play a role in regulating human decision-making and social behavior, but perhaps music itself evolved to promote group cohesion and social bonding. In any case, music is an emotional system arising through natural selection, yet it has undoubtedly become deeply connected to human social behavior. This study supports the hypothesis that music exists to promote socialization and maintain social cohesion, and is not merely an evolutionary byproduct or noise. This research also moves us a step closer toward elucidating not only the evolution and the biological function of music but also the evolution of human altruism.

\section{REFERENCES}

Aguiar, A., Brañas-Garza, P., and Miller, L. M. (2008). Moral distance in dictator games. Judgm. Decis. Mak. 3, 344-354.

Anshel, A., and Kipper, D. A. (1988). The influence of group singing on trust and cooperation. J. Music. Ther. 25, 145-155. doi: 10.1093/jmt/25.3.145

Balteş, F. R., Avram, J., Miclea, M., and Miu, A. C. (2011). Emotions induced by operatic music: psychophysiological effects of music, plot, and acting: a scientist's tribute to Maria Callas. Brain Cogn. 76, 146-157. doi: 10.1016/j.bandc.2011.01.012

Baron-Cohen, S., and Wheelwright, S. (2004). The empathy quotient: an investigation of adults with Asperger syndrome or high functioning autism, and normal sex differences. J. Autism Dev. Disord. 34, 163-175. doi: 10.102 3/B:JADD.0000022607.19833.00

Batson, C. D. (1991). The Altruism Question: Toward A Social-psychological Answer. Hillsdale, NJ: Lawrence Erlbaum Associates.

Baumgartner, T., Lutz, K., Schmidt, C. F., and Jäncke, L. (2006). The emotional power of music: how music enhances the feeling of affective pictures. Brain Res. 1075, 151-164. doi: 10.1016/j.brainres.2005.12.065

Baumgartner, T., Willi, M., and Jäncke, L. (2007). Modulation of corticospinal activity by strong emotions evoked by pictures and classical music: a transcranial magnetic stimulation study. Neuroreport 18, 261-265. doi: 10.1097/WNR.0b013e328012272e

Ben-Ner, A., Kramer, A., and Levy, O. (2008). Economic and hypothetical dictator game experiments: incentive effects at the individual level. J. Socio Econ. 37, 1775-1784. doi: 10.1016/j.socec.2007.11.004

Blood, A. J., and Zatorre, R. J. (2001). Intensely pleasurable responses to music correlate with activity in brain regions implicated in reward and emotion. Proc. Natl. Acad. Sci. U.S.A. 98, 11818-11823. doi: 10.1073/pnas.191355898

Bolton, G. E., Zwick, R., and Katok, E. (1998). Dictator game giving: rules of fairness versus acts of kindness. Int. J. Game Theory 27, 269-299. doi: 10.1007/s001820050072

Brattico, E., Alluri, V., Bogert, B., Jacobsen, T., Vartiainen, N., Nieminen, S., etal. (2011). A functional MRI study of happy and sad emotions in music with and without lyrics. Front. Psychol. 2:308. doi: 10.3389/fpsyg.2011. 00308

Budd, M. (1985). Music and the Emotions: The Philosophical Theories. London: Routledge \& Kegan Paul. 
Camerer, C. F., and Fehr, E. (2006). When does "economic man" dominate social behavior? Science 311, 47-52. doi: 10.1126/science.1110600

Capra, M. C. (2004). Mood-driven behavior in strategic interactions. Am. Econ. Rev. 94, 367-372. doi: 10.1257/0002828041301885

Chapin, H., Jantzen, K., Kelso, J. A., Steinberg, F., and Large, E. (2010). Dynamic emotional and neural responses to music depend on performance expression and listener experience. PLoS ONE 5:e13812. doi: 10.1371/journal.pone.0013812

Coricelli, G., Dolan, R. J., and Sirigu, A. (2007). Brain, emotion and decision making: the paradigmatic example of regret. Trends Cogn. Sci. 11, 258-265. doi: 10.1016/j.tics.2007.04.003

Costa, P. T. Jr., and McCrae, R. R. (1992). Revised NEO Personality Inventory (NEO PI-R) and NEO Five-Factor Inventory (NEO-FFI) Professional Manual. Odessa, FL: Psychological Assessment Resources.

Darwin, C. R. (1871). The Descent of Man, and Selection in Relation to Sex. London: John Murray. doi: 10.1037/12293-000

D’Ausilio, A., Altenmüller, E., Olivetti, B. M., and Lotze, M. (2006). Cross-moda plasticity of the motor cortex while listening to a rehearsed musical piece. Eur. J. Neurosci. 24, 955-958. doi: 10.1111/j.1460-9568.2006.04960.x

Decety, J. (2011). The neuroevolution of empathy. Ann. N. Y. Acad. Sci. 1231, 35-45 doi: 10.1111/j.1749-6632.2011.06027.x

Dovidio, J. F., Piliavin, J. A., Schroeder, D. A., and Penner, L. A. (2006). The Social Psychology of Prosocial Behavior. Mahwah, NJ: Lawrence Erlbaum Associates.

Engel, C. (2011). Dictator games: a meta study. Exp. Econ. 14, 583-610. doi: 10.1007/s10683-011-9283-7

Farrelly, D., Lazarus, J., and Gilbert, R. (2007). Altruists attract. Evol. Psychol. 5, 313-329.

Fehr, E., and Fischbacher, U. (2003). The nature of human altruism. Nature 425, 785-791. doi: 10.1038/nature02043

Fehr, E., Fischbacher, U., and Gächter, S. (2002). Strong reciprocity, human cooperation, and the enforcement of social norms. Hum. Nat. Int. Bios. 13, 1-25. doi $10.1007 / \mathrm{s} 12110-002-1012-7$

Fitch, W. T. (2006). The biology and evolution of music: a comparative perspective. Cognition 100, 173-215. doi: 10.1016/j.cognition.2005.11.009

Forgas, J. P., and Fiedler, K. (1996). Us and them: mood effects on intergroup discrimination. J. Pers. Soc. Psychol. 70, 28-40. doi: 10.1037//0022-3514.70.1.28

Forsythe, R., Horowitz, J. L., Savin, N. E., and Sefton, M. (1994). Fairness in simple bargaining experiments. GEB 6, 347-369. doi: 10.1006/game.1994.1021

Fried, R., and Berkowitz, L. (1979). Music hath charms....and can influence helpfulness. J. Appl. Soc. Psychol. 9, 199-208. doi: 10.1111/j.1559-1816.1979.tb0 2706.x

Gabrielsson, A. (2001). "Emotions in strong experiences with music," in Music and Emotion: Theory and Research, eds P. N. Juslin and J. A. Sloboda (Oxford: Oxford University Press), 431-449.

Gabrielsson, A., and Lindström, W. (2003). Strong experiences related to music: a descriptive system. Music. Sci. 7, 157-217.

Gendolla, G. H. E. (2000). On the impact of mood on behavior: an integrative theory and a review. Rev. Gen. Psychol. 4, 378-408. doi: 10.1037/1089-2680.4.4.378

Gino, F., Gu, J., and Zhong, C. B. (2009). Contagion or restitution? When bad apples can motivate ethical behavior. J. Exp. Soc. Psychol. 45, 1299-1302. doi: 10.1016/j.jesp.2009.07.014

Gintis, H. (2000). Strong reciprocity and human sociality. J. Theor. Biol. 206, 169179. doi: 10.1006/jtbi.2000.2111

Gosselin, N., Peretz, I., Johnsen, E., and Adolphs, R. (2007). Amygdala damage impairs emotion recognition from music. Neuropsychologia 45, 236-244. doi: 10.1016/j.neuropsychologia.2006.07.012

Gueguen, N. (2001). Effect of a perfume on prosocial behavior of pedestrians. Psychol. Rep. 88, 1046-1048. doi: 10.2466/pr0.2001.88.3c.1046

Hagen, E., and Bryant, G. (2003). Music and dance as a coalition signaling system. Hum. Nat. Int. Bios. 14, 21-51. doi: 10.1007/s12110-003-1015-z

Helsinki (2000). WMA Declaration of Helsinki - Ethical Principles for Medical Research Involving Human Subjects. (1964 updated in 2000). Helsinki: World Medical Association.

Henrich, J., Ensminger, J., McElreath, R., Barr, A., Barrett, C., Bolyanatz, A., et al. (2010). Markets, religion, community size, and the evolution of fairness and punishment. Science 327, 1480-1484. doi: 10.1126/science.1182238

Hodges, D. (2010). "Psychophysiological measures," in Handbook of Music and Emotion, eds P. N. Juslin and J. A. Sloboda (Oxford: Oxford University Press), 279-312.
Juslin, P. N., Liljeström, S., Västfjäll, D., and Lundqvist, L.-O. (2010). "How does music evoke emotions? Exploring the underlying mechanisms," in Handbook of Music and Emotion, eds P. N. Juslin and J. A. Sloboda (Oxford: Oxford University Press), 605-642.

Juslin, P. N., and Sloboda, J. A. (eds). (2010). Handbook of Music and Emotion. Oxford: Oxford University Press.

Kirschner, S., and Tomasello, M. (2009). Joint drumming: social context facilitates synchronization in preschool children. J. Exp. Child Psychol. 102, 299-314. doi: 10.1016/j.jecp.2008.07.005

Kirschner, S., and Tomasello, M. (2010). Joint music making promotes prosocial behavior in 4-year-old children. Evol. Hum. Behav. 31, 354-364. doi: 10.1016/j.evolhumbehav.2010.04.004

Knafo, A., Israel, S., Darvasi, A., Bachner-Melman, R., Uzefovsky, F., Cohen, L., et al. (2008). Individual differences in allocation of funds in the dictator game associated with length of the arginine vasopressin 1a receptor RS3 promoter region and correlation between RS3 length and hippocampal mRNA. Genes Brain Behav. 7, 266-275. doi: 10.1111/j.1601-183X.2007.00341.x

Koelsch, S., Fritz, T., von Cramon, D. Y., Müller, K., and Friederici, A. D. (2006). Investigating emotion with music: an fMRI study. Hum. Brain Mapp. 27, 239-250. doi: $10.1002 / \mathrm{hbm} .20180$

Koelsch, S., Siebel, W. A., and Fritz, T. (2010). "Functional neuroimaging," in Handbook of Music and Emotion, eds P. N. Juslin and J. A. Sloboda (Oxford: Oxford University Press), 314-344.

Kokal, I., Engel, A., Kirschner, S., and Keysers, C. (2011). Synchronized drumming enhances activity in the caudate and facilitates prosocial commitment-if the rhythm comes easily. PLoS ONE 6:e27272. doi: 10.1371/journal.pone.0027272

Konečni, V. J., Crozier, J. B., and Doob, A. N. (1976). Anger and expression of aggression: effects on aesthetic preference. Scientific Aesthetics 1, 47-55.

Koscik, T. R., and Tranel, D. (2011). The human amygdala is necessary for developing and expressing normal interpersonal trust. Neuropsychologia 49, 602-611. doi: 10.1016/j.neuropsychologia.2010.09.023

Lerner, J. S., Small, D. A., and Loewenstein, G. (2004). Heart strings and purse strings: carryover effects of emotions on economic decisions. Psychol. Sci. 15, 337-341. doi: 10.1111/j.0956-7976.2004.00679.x

Lerner, Y., Papo, D., Zhdanov, A., Belozersky, L., and Hendler, T. (2009). Eyes wide shut: amygdala mediates eyes-closed effect on emotional experience with music. PLoS ONE 4:e6230. doi: 10.1371/journal.pone.0006230

Locey, M. L., Jones, B. A., and Rachlin, H. (2011). Real and hypothetical rewards. Judgm. Decis. Mak. 6, 552-564.

Matthews, B. R., Chang, C. C., De May, M., Engstrim, J., and Miller, B. L. (2009). Pleasurable emotional response to music: a case of neurodegenerative generalized auditory agnosia. Neurocase 15, 248-259. doi: 10.1080/13554790802632934

McEwen, B. S. (2012). Brain on stress: how the social environment gets under the skin. Proc. Natl. Acad. Sci. U.S.A. 109, 17180-17185. doi: 10.1073/pnas.1121254109

Merker, B. (2000). "Synchronous chorusing and human origins," in The Origins of Music, eds N. L. Wallin, B. Merker, and S. Brown (Cambridge, MA: MIT Press), 315-327.

Miller, P. A., Bernzweig, J., Eisenberg, N., and Fabes, R. A. (1991). "The development and socialization of prosocial behavior," in Cooperation and Prosocial Behavior, eds R. A. Hinde and J. Groebel (New York: Cambridge University Press), 54-77.

Nakahara, H., Furuya, S., Masuko, T., Francis, P. R., and Kinoshita, H. (2011). Performing music can induce greater modulation of emotion-related psychophysiological responses than listening to music. Int. J. Psychophysiol. 81, 152-158. doi: 10.1016/j.ijpsycho.2011.06.003

North, A. C., and Hargreaves, D. J. (1998). The effect of music on atmosphere and purchase intentions in a cafeteria. J. Appl. Psychol. 28, 2254-2273. doi: 10.1111/j.1559-1816.1998.tb01370.x

North, A. C., Tarrant, M., and Hargreaves, D. J. (2004). The effects of music on helping behaviour: a field study. Environ. Behav. 36, 266-275. doi: $10.1177 / 0013916503256263$

Nusbaum, E. C., and Silvia, P. J. (2010). Shivers and timbres: personality and the experience of chills from music. Soc. Psychol. Personal Sci. 2, 199-204. doi: $10.1177 / 1948550610386810$

Overy, K., and Molnar-Szakacs, I. (2009). Being together in time: musical experience and the mirror neuron system. Music Percept. 26, 489-504. doi: 10.1525/mp.2009.26.5.489 
Patel, A. D. (2008). Music, Language, and the Brain. New York: Oxford University Press.

Pin, K. J., and Fletcher, B. C. (2011). Women's spending behaviour is menstrual-cycle sensitive. Pers. Indiv. Differ. 50, 74-78. doi: 10.1016/j.paid.2010.08.026

Radke, S., and de Bruijn, E. R. A. (2012). The other side of the coin: oxytocin decreases the adherence to fairness norms. Front. Hum. Neurosci. 6:193. doi: 10.3389/fnhum.2012.00193

Rand, D. G., Greene, J. D., and Nowak, M. A. (2012). Spontaneous giving and calculated greed. Nature. 489, 427-430. doi: 10.1038/nature11467

Ratner, K. G., Dotsch, R., Wigboldus, D. H., van Knippenberg, A., and Amodio, D. M. (2014). Visualizing minimal ingroup and outgroup faces: implications for impressions, attitudes, and behavior. J. Pers. Soc. Psychol. 106, 897-911. doi: $10.1037 / \mathrm{a} 0036498$

Riyanto, Y. E., and Zhang, J. (2010). "Does social comparison of ability reduce generosity? An experimental investigation," in A Boat Trip Through Economic Change: Proceedings of the IAREP/SABE/ICABEEP 2010 Conference, eds D. Fetchenhauer, J. Pradel, and E. Hoelzl (Cologne: International Association for Research in Economic Psychology), 193.

Rosenblat, T. S. (2008). The beauty premium: physical attractiveness and gender in dictator games. Negotiation J. 24, 465-481. doi: 10.1111/j.15719979.2008.00198.x

Rossi, V., and Pourtois, G. (2012). Transient state-dependent fluctuations in anxiety measured using STAI, POMS, PANAS or VAS: a comparative review. Anxiety Stress Coping 25, 603-645. doi: 10.1080/10615806.2011.582948

Salimpoor, V. N., Benovoy, M., Longo, G., Cooperstock, J. R., and Zatorre, R. J. (2009). The rewarding aspects of music listening are related to degree of emotional arousal. PLoS ONE 4:e7487. doi: 10.1371/journal.pone.0007487

Schwarz, N. (2000). Emotion, cognition, and decision making. Cogn. Emot. 14, 433-440. doi: 10.1080/026999300402745

Silka, J. B., and Housea, B. R. (2011). Evolutionary foundations of human prosocial sentiments. Proc. Natl. Acad. Sci. U.S.A. 108, 10910-10917. doi: 10.1073/pnas. 1100305108

Sloboda, J. A., and Juslin, P. N. (2010). "At the interface between the inner and outer world," in Handbook of Music and Emotion, eds P. N. Juslin and J. A. Sloboda (Oxford: Oxford University Press), 73-97.

Spielberger, C. D., Gorsuch, R. L., and Lushene, R. E. (1970). Manual for the StateTrait Anxiety Inventory. Palo Alto, CA: Consulting Psychologists Press.

Tan, H. B., and Forgas, J. P. (2010). When happiness makes us selfish, but sadness makes us fair: affective influences on interpersonal strategies in the dictator game. J. Exp. Soc. Psychol. 46, 571-576. doi: 10.1016/j.jesp.2010. 01.007
The Japan Foundation (2012). Great East Japan Earthquake Commemoration Free Concert OVERCOMING THE DISASTER: GRATITUDE FROM JAPAN TO THE WORLD. Available at: http://gratitude-concert-march6.org/concert.htm [accessed September 9, 2013].

Tomasello, M., Carpenter, M., Call, J., Behne, T., and Moll, H. (2005). Understanding and sharing intentions: the origins of cultural cognition. Behav. Brain Sci. 28, 675-691. doi: 10.1017/S0140525X05000129

Tricomi, E., Rangel, A., Camerer, C. F., and O’Doherty, J. P. (2010). Neural evidence for inequality-averse social preferences. Nature 463, 1089-1091. doi: 10.1038/nature08785

Trost, W., Ethofer, T., Zentner, M., and Vuilleumier, P. (2012). Mapping aesthetic musical emotions in the brain. Cereb. Cortex 22, 2769-2783. doi: 10.1093/cercor/bhr353

van Honk, J., Eisenegger, C., Terburg, D., Stein, D. J., and Morgan, B. (2013). Generous economic investments after basolateral amygdala damage. Proc. Natl. Acad. Sci.U.S.A. 110, 2506-2510. doi: 10.1073/pnas.1217316110

Wallin, N. L., Merker, B., and Brown, S. (2000). The Origins of Music. Cambridge, MA: MIT Press.

Wilson, C. W., and Hopkins, B. L. (1973). The effects of contingent music on the intensity of noise in junior-high home economics classes. J. Appl. Behav. Anal. 6, 269-275. doi: 10.1901/jaba.1973.6-269

Wright, W. F., and Bower, G. H. (1992). Mood effects on subjective probability assessment. Organ. Behav. Hum. Decis. Process. 52, 276-291. doi: 10.1016/07495978(92)90039-A

Zatorre, R., and McGill, J. (2005). Music, the food of neuroscience? Nature 434, 312-315. doi: $10.1038 / 434312 \mathrm{a}$

Conflict of Interest Statement: The authors declare that the research was conducted in the absence of any commercial or financial relationships that could be construed as a potential conflict of interest.

Received: 07 May 2014; accepted: 07 October 2014; published online: 28 October 2014. Citation: Fukui $H$ and Toyoshima $K$ (2014) Chill-inducing music enhances altruism in humans. Front. Psychol. 5:1215. doi: 10.3389/fpsyg.2014.01215

This article was submitted to Cognition, a section of the journal Frontiers in Psychology. Copyright (C) 2014 Fukui and Toyoshima. This is an open-access article distributed under the terms of the Creative Commons Attribution License (CC BY). The use, distribution or reproduction in other forums is permitted, provided the original author(s) or licensor are credited and that the original publication in this journal is cited, in accordance with accepted academic practice. No use, distribution or reproduction is permitted which does not comply with these terms. 